\title{
Genetic and ontogenetic variation in behaviour: its possible role in the maintenance of genetic variation in the wing dimorphism of Gryllus firmus
}

\author{
DEREK A. ROFF \& PATRICK SHANNON \\ Department of Biology, McGill University, 1205 Dr Penfield Ave, Montreal, Quebec, Canada, H3A $1 B 1$
}

\begin{abstract}
Genetic variation may be preserved in populations by several different modes of behaviour. In this paper we examine the consequences of behaviour on genetic variation in traits that are determined by genetic factors and by environmental conditions experienced during ontogeny. The particular trait considered is wing dimorphism in the sand cricket Gryllus firmus. In this species, as is typical of wing dimorphic insects, the adult wing morph (macropterous or micropterous) is determined by both genetic constitution and the temperature experienced during a specific period of nymphal development. Wing morph may thus be controlled, in part, by the thermal preference of nymphs. The effective heritability of wing morphology will be increased if nymphs with a genetic disposition to a particular wing morph select the temperature that causes that morph to be expressed. By contrast, effective heritability will be decreased if nymphs show no preference, or nymphs select temperatures that reduce phenotypic variation among individuals. During the period of ontogeny when future wing morph is sensitive to temperature, nymphal crickets that are genetically disposed to become macropterous select lower temperatures than crickets that have the opposite genetic disposition. Likewise, nymphs that are being raised under conditions promoting macroptery select lower temperatures than nymphs being raised under conditions favouring microptery. The consequence of this behaviour is that genetic variation for wing morph may be masked, and hence preserved.
\end{abstract}

Keywords: behaviour, genetic variation, Gryllus firmus, thermal preference, wing dimorphism.

\section{Introduction}

The maintenance of genetic variation in natural populations is a central problem of evolutionary theory (Wright, 1978; Grant \& Price, 1981; Roff \& Mousseau, 1987; Mousseau \& Roff, 1987). Habitat selection has been implicated as a possible behavioural mechanism: according to this hypothesis genotypes select habitats in which their fitnesses are maximized (Hedrick, 1986; Jaenike \& Holt, 1991). As a consequence of this behaviour, expressed genetic variation is enhanced, but maintained because of spatial segregation. An alternative mechanism is exemplified by sex ratio in turtles.

In turtles, sex is determined by the temperature at which the egg develops, but at any given temperature

Correspondence: Dr D. A. Roff, Department of Biology, McGill University, 1205 Dr Penfield Ave, Montreal, Quebec, Canada, H3A 1B1. the ratio varies between families, suggesting a genetic component to the determination of sex (Bull et al., 1982; Janzen, 1992). The heritability of sex ratio $\left(h^{2}\right)$ can be estimated using the threshold model of quantitative genetics (Bull et al., 1982): in the Ouachita map turtle, Graptemys ouachitensis, $h^{2}$ was estimated to be 0.82 (Bull et al., 1982), and in the common snapping turtle, Chelydra serpentina, $h^{2}$ was estimated to be 0.56 (Janzen, 1992). These heritabilities are large for a trait that is presumably under strong selection. However, variation in temperature among nests may considerably inflate the environmental variance: assuming no covariance between nest temperature and genotype, the effective heritability $\left(h^{2}{ }_{\mathrm{e}}\right)$ (Bull et al., 1982) is given by the following formula:

$$
h_{\mathrm{e}}^{2}=\frac{h^{2} \sigma_{\mathrm{p}}^{2}}{\sigma_{\mathrm{p}}^{2}+\sigma_{\mathrm{t}}^{2}},
$$


where $h^{2}$ is the heritability of sex ratio, $\sigma_{\mathrm{p}}^{2}$ is the phenotypic variance, and $\sigma_{\mathrm{t}}^{2}$ is the variance in nest temperature. Bull et al. (1982) estimated the phenotypic variance to be approximately 0.09 , and the variance in nest temperature as 1 , giving effective heritabilities of 0.06 and 0.04 for the map and snapping turtle, respectively. Thus, the additive genetic variance for sex ratio may be, to a large extent, masked by the random choice by the female of the nest temperature. No evidence exists that females select nest sites randomly with respect to temperature variation. If females that had a genetic disposition to produce females selected temperatures that favoured the production of females, while females that had a genetic disposition to produce males selected temperatures that favoured the production of males, the effective heritability would be increased. On the other hand, if females showed the opposite preference (e.g. 'female-producing' females selected temperatures that favoured males), effective heritability would be decreased.

Many attributes, particularly morphological characteristics, are determined during particular periods of ontogeny and in such periods, as with sex in turtles, the future manifestation of the trait is sensitive to environmental influences. As shown by the above example of sex ratio in turtles, behavioural differences among genotypes can affect the expression of genetic variation for the trait. In this paper we report on an experiment designed to examine genetic differences in the thermal preference of nymphs of the sand cricket Gryllus firmus, during the period in which adult wing morph is sensitive to temperature.

G. firmus is a ground-dwelling cricket distributed over the south-eastern United States (Alexander, 1968) and Bermuda (Kevan, 1980). Two wing morphs occur: a long-winged, macropterous morph that is capable of flight, and a short-winged, micropterous morph that cannot fly. Variation is discontinuous, less than 1.5 per cent having wings of intermediate length (Roff, 1986). Under a constant temperature the heritability of wing form in G. firmus is high, as estimated both by full sib analysis ( $h^{2}=0.65$; Roff, 1986) and selection $\left(h^{2}=0.60 ;\right.$ Roff, 1990a). However, the expression of the trait is strongly modified by temperature, high temperatures producing an increased frequency of macropterous adults (Roff, 1986; unpublished data). In crickets, changes in environmental temperature influence future wing morph only if experienced before a critical stage of development (Tanaka, 1978; Zera \& Tiebel, 1988). Therefore, in a variable thermal regime the effective heritability of the trait will be enhanced if individuals genetically predisposed to become macropterous select high temperatures during this critical period, while individuals genetically predisposed to become micropterous select low temperatures. On the other hand, effective heritability will be reduced if the preferences are reversed, or there is no covariance between genotype and temperature.

\section{Methods}

To examine the relationship between genotype and thermal preference we used three lines of crickets: individuals from a stock maintained without selection $(\mathrm{C}$ line), individuals from a line selected for high incidence of macroptery ( $\mathrm{L}$ line), and individuals from a line selected for low incidence of macroptery ( $\mathrm{S}$ line; for details of the selection protocol see Roff, 1990a). For these experiments crickets were raised at $28^{\circ} \mathrm{C}$ and a photoperiod of $16 \mathrm{~h}$ light $(16 \mathrm{~L}): 8 \mathrm{~h}$ darkness $(8 \mathrm{D})$, under which conditions the proportion of macropterous individuals in the $\mathrm{L}$ line was greater than 90 per cent, in the $\mathrm{S}$ line less than 10 per cent, and in the $\mathrm{C}$ line approximately 50 per cent. In Drosophila pseudoobscura both genotype and rearing conditions affect thermal preference (Taylor, 1986). Therefore, in addition to testing the thermal preference among lines, we examined the thermal preference of nymphs from the $\mathrm{C}$ line being raised under a relatively short photoperiod (12L:12D; this line is termed C12 here, while for clarity the control line raised at $16 \mathrm{~L}: 8 \mathrm{D}$ will be designated C16). The nymphs from $\mathrm{C} 12$ yielded $10-15$ per cent macroptery.

\section{Transfer experiments}

To determine the critical period during which temperature influences the adult wing morphology we performed two experiments, in which nymphs were transferred at different ages from a high temperature $\left(28^{\circ} \mathrm{C}\right)$ rearing regime to a low temperature $\left(25^{\circ} \mathrm{C}\right)$ rearing regime. Juvenile crickets transferred from the high rearing temperature to the lower rearing temperature express the adult phenotype typical of rearing at the lower temperature (i.e. micropterous) until the critical period is passed, after which the incidence of macroptery equals that obtained for crickets raised throughout at the high temperature.

In the first transfer experiment, 16 cages of newly hatched crickets from the $\mathrm{C}$ line were set up at $28^{\circ} \mathrm{C}$. Each cage (plastic mouse cages measuring $29 \mathrm{~cm}$ long $\times 19 \mathrm{~cm}$ wide $\times 13 \mathrm{~cm}$ high) contained 60 hatchlings, with food (crushed rabbit chow and lettuce) and water supplied ad libitum as described in Roff (1986). Based on preliminary experiments we ascertained that the critical period was surpassed about halfway through the developmental period, which takes about 40 days. At 5, 10, 15 and 20 days after hatching, all 
individuals from four cages were transferred to $25^{\circ} \mathrm{C}$. Wing morph was scored at adult moult. Two control groups (three cages each) were raised from 1 day after hatching at $25^{\circ} \mathrm{C}$ and $28^{\circ} \mathrm{C}$. All cages were maintained in a $16 \mathrm{~L}: 8 \mathrm{D}$ photoperiod.

For the second experiment, individuals from the $\mathrm{L}$ line were isolated singly at 1 day after hatching in clear plastic sandwich boxes provided with crushed rabbit chow and water supplied from a glass vial plugged with cotton. Individuals were maintained at $28^{\circ} \mathrm{C}$ on a $16 \mathrm{~L}: 8 \mathrm{D}$ photoperiod. At $5,10,15$ and 20 days after hatching $40-60$ crickets were transferred to $25^{\circ} \mathrm{C}$. Two control groups of 60 individuals each were raised concurrently at either 28 or $25^{\circ} \mathrm{C}$.

\section{Gradient experiments}

Experimental apparatus. To determine the preferred temperatures of juvenile $G$. firmus we constructed temperature gradients as follows. Five 1000 watt strip heaters were set $40 \mathrm{~cm}$ apart and perpendicular to the long axis of three separate open-topped perspex boxes measuring $200 \mathrm{~cm}$ long $\times 18 \mathrm{~cm}$ wide $\times 22 \mathrm{~cm}$ high. The floors of the boxes were made of aluminium sheeting, $2 \mathrm{~mm}$ thick, painted white on the inside. Each heater was controlled independently by a thermostat attached directly to the heater, and fine control was achieved by a dimmer switch in series with the thermostat. The heaters were calibrated to produce a smooth temperature gradient on the inside surface of the bottom of each box ranging from $40^{\circ} \mathrm{C}$ at one end to $22^{\circ} \mathrm{C}$ at the other, dropping by $5.6^{\circ} \mathrm{C}$ every $40 \mathrm{~cm}$, temperatures being measured at the midline of each box. Temperatures across the width of the floor of the box did not vary by more than $1^{\circ} \mathrm{C}$ from the temperature in the middle. Four gradients were constructed and maintained side by side in a constant-temperature room at $21 \pm 2{ }^{\circ} \mathrm{C}$. Inside each box, food (crushed rabbit chow in $6 \mathrm{~cm}$ diameter petri dishes) and water (in glass vials plugged with cotton) were available every $40 \mathrm{~cm}$, although crickets placed on the gradients often transported pieces of rabbit chow more than $20 \mathrm{~cm}$ from a food dish before partially consuming them. Hence, although food was only placed at intervals, by the end of any given observation period it was often thinly available along the length of the gradient.

Measuring thermal preference. In each experiment observations of temperature selection were made on crickets aged 5, 10 and 15 days old. For each combination of age and treatment (lines L, S, C12, C16), 60 individuals were introduced onto a gradient and allowed to acclimatize for $10 \mathrm{~h}$. Thereafter, a single nymph was sampled, using random stratified sampling, every $0.5 \mathrm{~h}$ over $13 \mathrm{~h}$, giving a sample of 26 measurements per experiment. All experiments were replicated, giving (after discarding 15 measurements due to equipment failure) a total sample size of 609 individual measurements. In each case, thoracic temperature and surface temperature at the site occupied by the nymph (hereafter referred to as the 'surface temperature') were measured. Temperature preferences may be influenced by body size; therefore, in one set of replicates $(n=290)$, the nymph's right femur length was measured as an index of body size.

\section{Results}

\section{Transfer experiments}

The frequency of macropterous individuals differs between the sexes (Roff, 1986); therefore, the two sexes were analysed separately. There was no significant heterogeneity ( $\chi^{2}$ analysis, $P>0.1$ in all cases) among cages within a transfer group, or among the respective control groups, and hence the results from replicate cages were combined for analysis. For both males and females, the proportion of macropterous adults was significantly greater in control groups raised at $28^{\circ} \mathrm{C}$ than those raised at $25^{\circ} \mathrm{C}(P<0.01$; Fisher Exact Test).

Transfer from the high $\left(28^{\circ} \mathrm{C}\right)$ to the low $\left(25^{\circ} \mathrm{C}\right)$ temperature should produce the same proportion of macropterous adults as in the low temperature until the critical age is surpassed, after which the proportion should be the same as that obtained for crickets raised continually at the higher temperature. Visually, there is a large increase in the percentage macroptery in crickets transferred at day 20 (Fig. 1). To locate the switching point statistically we used a least squares approach. For each sex and experiment combination we sequentially divided the data set into two sections. Five groupings are possible: $\mathrm{C} 25$, and the rest; $\mathrm{C} 25+$ day 5 , and the rest; C25+day $5+$ day 10 , and the rest; $\mathrm{C} 25+$ day $5+$ day $10+$ day 15 , and the rest; $\mathrm{C} 25+$ day $5+$ day $10+$ day $15+$ day 20 , and C28. We next computed the sums of squared deviations, $S S$ :

$$
S S=\sum_{i=1}^{4}\left(\sum_{j=1}^{n}\left(p_{i, j}-\hat{p}_{i, j}\right)^{2}+\sum_{j=n+1}^{6}\left(p_{i, j}-\hat{p}_{i, j}\right)^{2}\right),
$$

where $p$ and $\hat{p}$ are, respectively, the proportion of macroptery and mean proportion of macroptery for a given sex/experiment/grouping combination; $i$ denotes sex/experiment combination, $j$ denotes grouping, and $n$ is the size of the first group (C25 is subscripted as $j=1$, day 5 as $j=2$, etc). As indicated above, there are five possible groupings: in ascending order of $n$, the values 


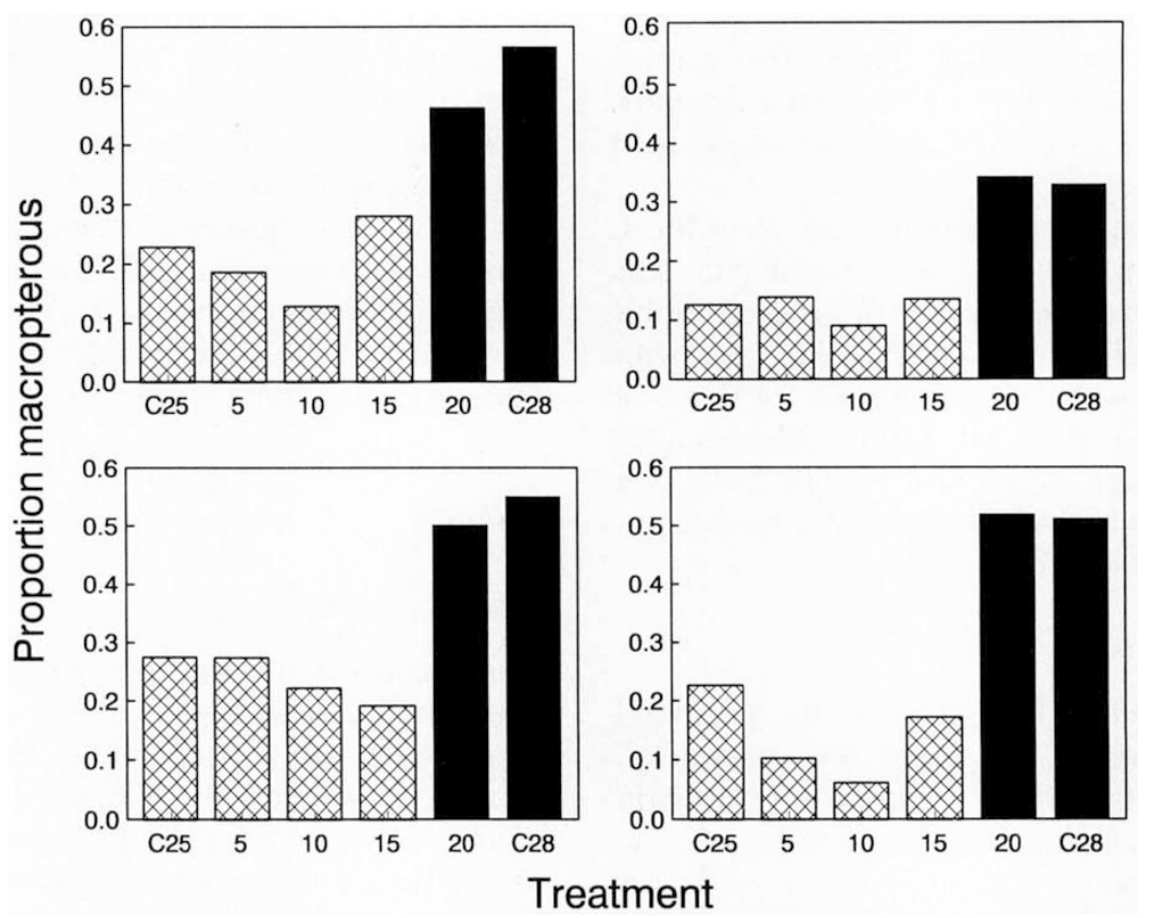

Fig. 1 Proportion of macropterous adults produced by transfer of nymphs from $28^{\circ} \mathrm{C}$ to $25^{\circ} \mathrm{C}$ at each of 4 ages $(5,10,15$ and 20 days), as well as that of controls raised throughout at $25^{\circ} \mathrm{C}(\mathrm{C} 25)$ and $28^{\circ} \mathrm{C}(\mathrm{C} 28)$. Upper $\mathrm{C}$ line (Expt. 1); lower $\mathrm{L}$ line (Expt. 2). Left panels, females; right panels, males. Histograms shaded with cross-hatching are not significantly different from $\mathrm{C} 25$, while those in black are not significantly different from C 28 .

of $S S$ obtained were $0.51,0.44,0.25,0.04$ and 0.30 . There is a dramatic decrease in $S S$ for the grouping C25 + day $5+$ day $10+$ day 15 vs. day $20+\mathrm{C} 28$, as might be expected from the relatively high proportion of macroptery obtained from day 20 and C28 cages (Fig. 1). For cases in which groups consist of at least two values, statistical significance can be measured with a two-way ANOvA using the two factors, sex/experiment and grouping. In ascending order of $n$, the probabilities associated with each group are: $P=0.11$ $(n=2), P<0.001(n=3)$, and $P<0.000001(n=4$; all tests were performed with both the raw data and arcsine-square root transformed data: the results did not differ).

As a further test we made pairwise comparisons between the transfer and control groups, using onetailed Fisher Exact Tests. This analysis confirmed the least squares results: nymphs transferred at days 5,10 and 15 were not significantly different from the C25 line, but were significantly different from those transferred at day 20 or maintained throughout at $28^{\circ} \mathrm{C}$ (C28).

The results of these two experiments indicate that the critical age at which adult wing morph is sensitive to temperature lies between day 15 and day 20 posthatch and, therefore, that temperature preferences prior to day 15 can influence the adult wing form.

\section{Thermal preference}

Body temperatures (Fig. 2a) were $2-4^{\circ} \mathrm{C}$ lower than surface temperature (Fig. 2b). Both body temperature and surface temperature differed significantly with age and treatment (Fig. 2, Table 1): older crickets selected higher temperatures, while crickets predisposed to become macropterous, either because of their genetic constitution (L group) or their rearing regime (C16 group), selected lower temperatures than those predisposed to become micropterous (groups C12 and S).

Both body and surface temperature were significantly correlated with femur length (for body temperature, $F_{1,288}=131.6, \quad P<0.0001$; for surface temperature, $\left.F_{1,288}=48.4, \quad P<0.0001\right)$. Body size effects were removed by using the residuals from the fitted regressions: there was still a highly significant effect due to treatment (Fig. 3: for body size, $F_{3,286}=34.2, \quad P<0.0001$; for surface temperature, $\left.F_{3,286}=48.44, P=0.023\right)$. As found in the previous 

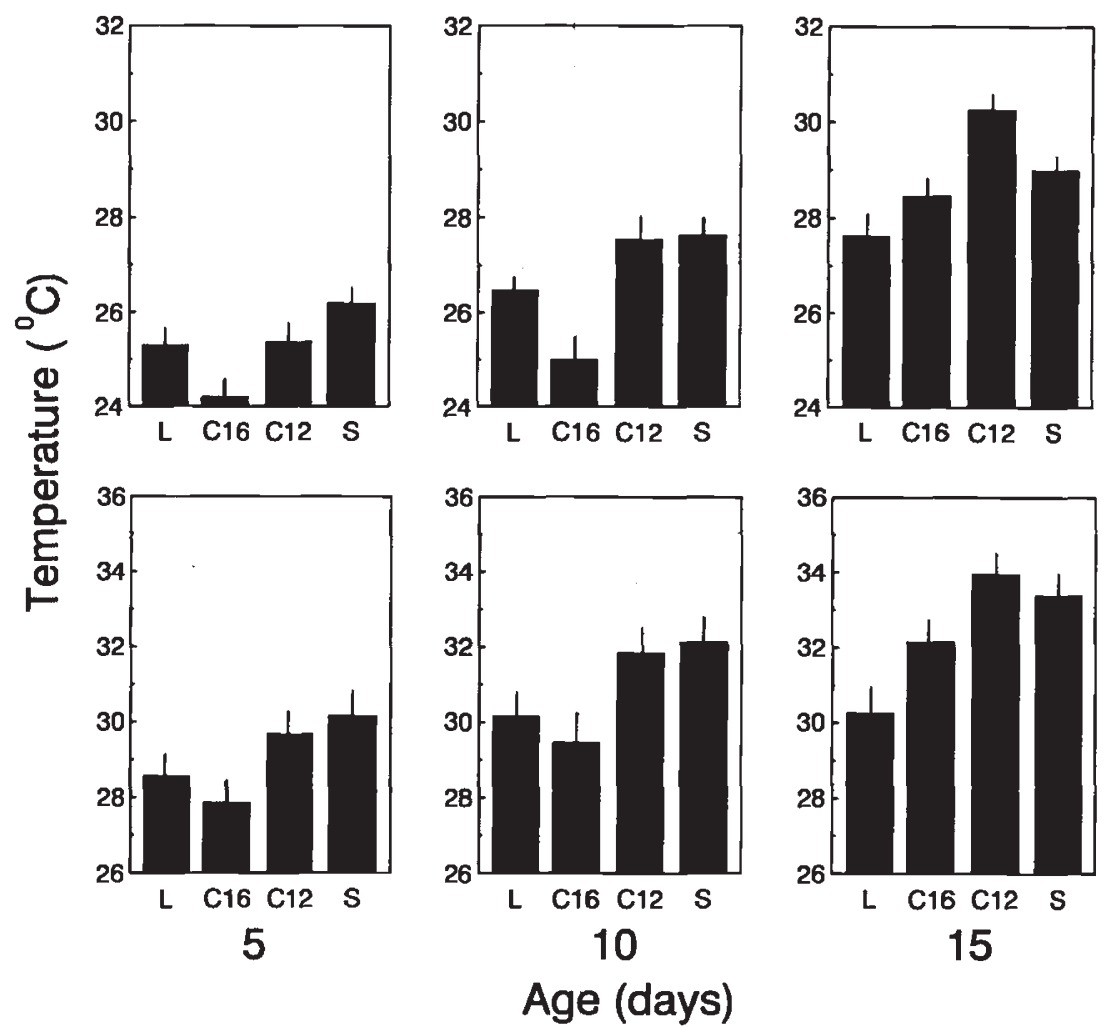

Fig. 2 Body temperatures (upper panel) and surface temperatures (lower panel) of the four treatment groups at days 5, 10 and 15 post-hatching. Error bars give \pm 1 S.E. Histograms are ranked according to the incidence of macroptery (from left to right, high to low incidence).

Table 1 ANOVA results of the analysis of body temperatures and surface temperatures, analysed by age, treatment, and replicate gradient (Box)

\begin{tabular}{lrlc}
\hline Factor & \multicolumn{1}{l}{ d.f. } & $P$ \\
\hline Body temperatures & & & \\
Age & 101.0 & 2,598 & $<0.0001$ \\
Box & 0.3 & 3,598 & 0.92 \\
Treatment & 18.8 & 3,598 & $<0.0001$ \\
Surface temperatures & & & \\
Age & 27.7 & 2,598 & $<0.0001$ \\
Box & 0.2 & 3,598 & 0.90 \\
Treatment & 11.7 & 3,598 & $<0.0001$ \\
\hline
\end{tabular}

No interaction terms were significant.

analysis, $\mathrm{S}$ and $\mathrm{C} 12$ nymphs consistently preferred higher temperatures than either L or C16 nymphs.

\section{Discussion}

At all levels of analysis, treatment had a consistent and significant effect on the surface temperature or body temperature selected by nymphal crickets during the period in development when their future wing morph was still sensitive to rearing temperature. Those crickets that would normally be predisposed to become micropterous, whether by photoperiodic cues or by genotype, chose higher temperatures than those predisposed to macroptery. The difference in temperatures selected by the nymphal crickets could have a significant impact on the expression of wing dimorphism. Body temperatures ranged from approximately $24^{\circ} \mathrm{C}$ to $30^{\circ} \mathrm{C}$ (Fig. 2): over this range the incidence of macroptery varies from 2 per cent to 75 per cent in unselected crickets (Roff, unpub. obs.).

As the crickets aged they tended to select higher temperatures, which would reduce the range of macroptery expected, but even at 15 days the temperature range selected $\left(27.6-30.3^{\circ} \mathrm{C}\right)$ will generate a range in macroptery ranging from 50 per cent to 75 per cent (Roff, 1986). These experiments suggest that thermoregulatory behaviour could reduce the effect of selection on wing morph, since the behaviour lowers the effective heritability of wing morph by decreasing the phenotypic variance between genotypes, and by so 

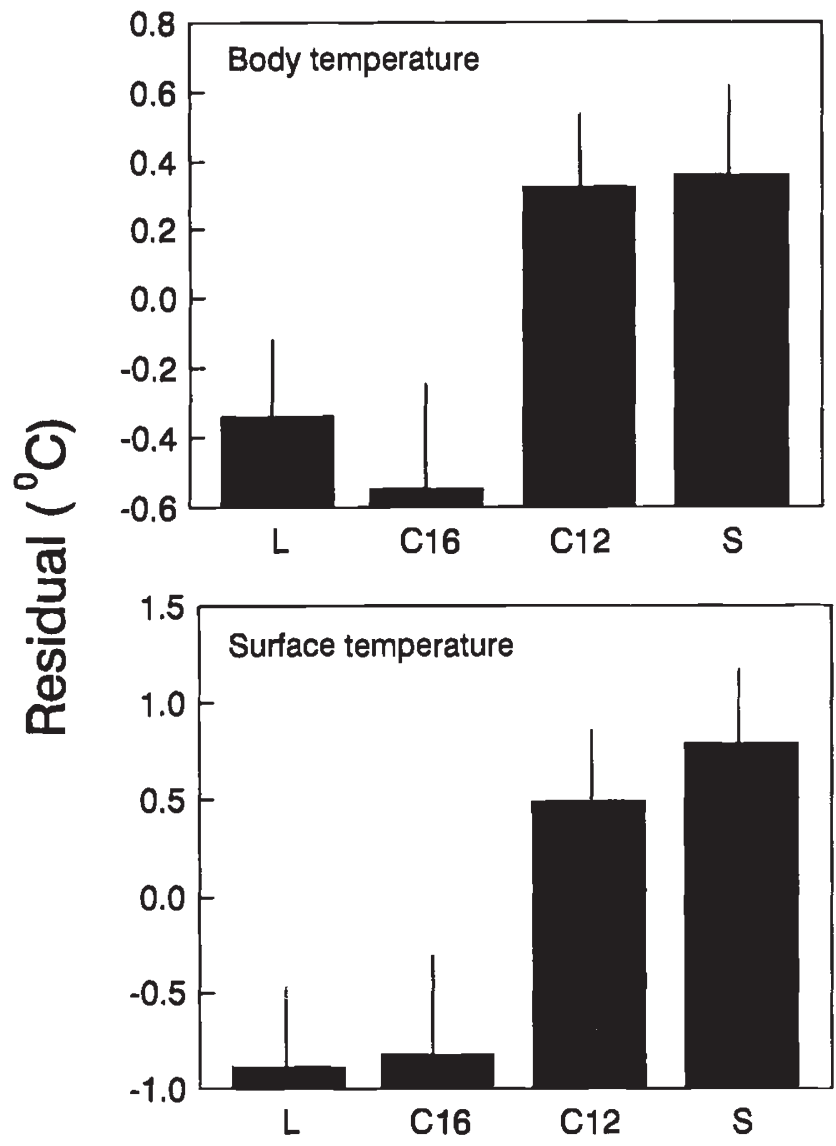

Fig. 3 Mean residual body temperature (upper panel) and surface temperature (lower panel) from regressions of body and surface temperature on femur length. Error bars give mean \pm 1 S.E. Histograms are ranked according to the incidence of macroptery (from left to right, high to low incidence).

doing would slow the course of selection. Whether the thermal preferences increase fitness cannot be assessed, and we do not suggest that the correlation between genotype and thermal preference has been directly selected. The important point is that this correlation, arising for whatever reason, will tend to mask genetic variation.

Preferred temperature increased with body size (as measured by femur length). Individuals choosing lower temperatures may do so to avoid desiccation (Willmer, 1985), so that the potential effect on wing morph is only incidental. However, the effect of treatment on thermal preference was significant after the effect of body size was removed, suggesting that body size was not the principal factor causing differences in behaviour. The similarity in preferred temperature between groups genetically and environmentally predisposed to the same wing morph (i.e. L and C16, vs. S and C12) suggests a similar underlying physiological mechanism.
However, if the behaviour were entirely due to the propensity to become macropterous, the temperature preferences should increase in the order $\mathrm{L}<\mathrm{C} 16<\mathrm{C} 12<\mathrm{S}$, matching the order of proportion macroptery (see Introduction). At 5 and 10 days posthatch the order was $\mathrm{C} 16<\mathrm{L}<\mathrm{C} 12<\mathrm{S}$ (Fig. 2), while at 15 days it was $\mathrm{L}<\mathrm{C} 16<\mathrm{S}<\mathrm{C} 12$. There was also no consistent pattern in rankings for the residual analysis (Fig. 3). These results suggest that thermal preferences are controlled by several factors, one of which is wing form propensity. Only further systematic experiments can elucidate the other determinants.

It should be emphasized that we have not demonstrated that the differences in temperature preference between groups actually resulted in an altered production of macropterous adults. Further experiments will require the rearing of the various groups both in the presence and absence of thermal heterogeneity, as well as concomitant estimation of preferred temperatures. However, as noted above, the differences in preferred body temperatures are enough to affect the proportions of macropterous individuals produced.

\section{Acknowledgements}

We gratefully thank S. David, T. Walsh, T. Briza, R. LaMarsh, and K. Webb for technical assistance. The comments of Drs D. J. Fairbairn, Y. Carrière, D. Kramer, and W. Blanckenhorn were most helpful in improving the clarity of the manuscript. This research was supported by an operating grant from the Natural Sciences and Research Council of Canada to D. A. R.

\section{References}

ALEXANDER, R. D. 1968. Life cycles, specialization and related phenomena in crickets. Quart. Rev. Biol., 43, 1-41.

BULL, J. J., VOGT, R. C. AND BULMER, M. G. 1982. Heritability of sex ratio in turtles with environmental sex determination. Evolution, 36, 333-341.

GRANT, P. R. AND PRICE, T. D. 1981. Population variation in continuously varying traits as an ecological genetic problem. Am. Zool., 21, 795-811.

HEDRICK, P. W. 1986. Genetic polymorphism in heterogeneous environments: a decade later. Annu. Rev. Ecol. Syst., 17, 535-566.

JANZEN, F. J. 1992. Heritable variation for sex ratio under environmental sex determination in the common snapping turtle (Chelydra serpentina). Genetics, 131, 155-161.

JAENIKE, J. AND HOLT, R. D. 1991. Genetic variation for habitat preference: Evidence and explanations. Am. Nat., 137 (supplement), S67-S90.

KEVAN, D. M. 1980. The taxonomic status of the Bermuda beach cricket (Orthopera: Gryllidae). Syst. Ent., 5, 83-95.

MOUSSEAU, T. A. AND ROFF, D. A. 1987. Natural selection and the heritabilities of fitness components. Heredity, 59, 181-197. 
ROFF, D. A. 1986. The genetic basis of wing dimorphism in the sand cricket Gryllus firmus and its relevance to the evolution of wing dimorphism in insects. Heredity, 57, 221-231.

ROFF, D. A. 1990a. Selection for changes in the incidence of wing dimorphism in Gryllus firmus. Heredity, 65, 163-168.

RoFF, D. A. 1990b. Antagonistic pleiotropy and the evolution of wing dimorphism in the sand cricket, Gyrllus firmus. Heredity, 65, 169-177.

ROFF, D. A. AND MOUSSEAU, T. A. 1987. Quantitative genetics and fitness: lessons from Drosophila. Heredity, 58, 103-118.

TANAKA, s. 1978. Photoperiodic determination of wing form in Pteronemobius nitidus Bolivar (Orthoptera, Gryllidae). Kontyu, 46, 207-214.

TAYLOR, C. E. 1986. Habitat choice in Drosophila pseudoobscura: the roles of genotype and of experience. Behav. Genet., 16, 271-279.

WILLMER, P. G. 1985. Size effects on hygrothermal balance and foraging behaviour in a specid wasp, cerceris arenaria. Ecol. Ent., 10, 469-479.

WRIGHT, s. 1978. Evolution and Genetics of Populations, vol. 4, University of Chicago Press.

ZERA, A. J. AND TIEBEL, K. C. 1988. Brachypterizing effect of group rearing, juvenile hormone III and methroprene in the wing-dimorphic cricket, Gryllus rubens. J. Insect Physiol., 34, 489-498. 